\title{
Costly plastic morphological responses to predator specific odour cues in three-spined sticklebacks (Gasterosteus aculeatus)
}

\author{
Joachim G. Frommen • Fabian Herder • Leif Engqvist • \\ Marion Mehlis • Theo C. M. Bakker • Julia Schwarzer • \\ Timo Thünken
}

Received: 8 March 2010/Accepted: 30 November 2010/Published online: 14 December 2010

(C) Springer Science+Business Media B.V. 2010

\begin{abstract}
Predation risk is one of the major forces affecting phenotypic variation among and within animal populations. While fixed anti-predator morphologies are favoured when predation level is consistently high, plastic morphological responses are advantageous when predation risk is changing temporarily, spatially, or qualitatively. Three-spined sticklebacks (Gasterosteus aculeatus) are well known for their substantial variability in morphology, including defensive traits. Part of this variation might be due to phenotypic plasticity. However, little is known about sticklebacks' plastic ability to react morphologically to changing risks of predation and about the proximate cues involved. Using a split-clutch design we show that odour of a predatory fish induces morphological changes in sticklebacks. Under predation risk, i.e., when exposed to odour of a predator, fish grew faster and developed a different morphology, compared to fish reared under low predation risk, i.e., exposed to odour of a non-predatory fish, or in a fish-free environment. However, fast growing comes at cost of increased body asymmetries suggesting developmental constraints. The results indicate that sticklebacks are able to distinguish between predatory and non-predatory fishes by olfactory cues alone. As fishes were fed on invertebrates, this reaction was not induced by chemical cues of digested conspecifics, but rather by predator cues themselves. Further, the results show that variation in body morphology in sticklebacks has not only a strong genetical component, but is also based on plastic responses to
\end{abstract}

J. G. Frommen · L. Engqvist · M. Mehlis · T. C. M. Bakker · T. Thünken Institute for Evolutionary Biology and Ecology, University of Bonn, An der Immenburg 1, 53121 Bonn, Germany

J. G. Frommen $(\bowtie)$

Konrad Lorenz Institute for Ethology, Austrian Academy of Sciences,

Savoyenstr. 1a, 1160 Vienna, Austria

e-mail: j.frommen@klivv.oeaw.ac.at

F. Herder · J. Schwarzer

Department of Ichthyology, Zoologisches Forschungsmuseum Alexander Koenig, Adenauerallee 160, 53113 Bonn, Germany

L. Engqvist

Theoretical Biology Group, Centre for Ecological and Evolutionary Studies, University of Groningen, P.O. Box 11103, 9700 CC Groningen, The Netherlands 
different environments, in our case different predation pressures, thus opening new questions for this model species in ecology and evolution.

Keywords Phenotypic plasticity · Reaction norm - Predation risk · Induced defences · Speciation $\cdot$ Schreckstoff

\section{Introduction}

Understanding the evolution and maintenance of phenotypic variation within and among populations is of major interest in evolutionary ecology. Phenotypic plasticity, i.e., the ability of a single genotype to produce different phenotypes in response to environmental variation (see West-Eberhard 1989 for a review), may enable individuals to cope with new environmental challenges and thus might facilitate colonisation of new habitats and persistence under alternative ecological frameworks (Price et al. 2003; Wund et al. 2008). Phenotypic plasticity increases variability, on which selection can operate, possibly resulting in genetic assimilation, i.e., genetic changes in the same direction (Waddington 1942; Crispo 2007), eventually further reinforcing phenotypic differentiation (Pfennig et al. 2010). Thus, plasticity might be an important prerequisite for genetic evolution: not only it represents a new source of variability, but it can be, itself, exposed to selection (Scheiner 1993; Schlichting and Pigliucci 1998; Pigliucci 2001).

Predation is one of the most crucial ecological factors influencing population dynamics and diversification processes (Nosil and Crespi 2006). In the continuous presence of predators, defensive structures or features have evolved in several groups of organisms (e.g., Endler 1995; Tollrian and Harvell 1999), leading to phenotypic differentiation between populations. Some of these differentiations have been shown to be genetically based (e.g., Peichel et al. 2001; McKinnon and Rundle 2002; Langerhans et al. 2004). However, anti-predator traits are often costly to maintain and thus disadvantageous in predator-free environments (Harvell 1990). Therefore, when predation pressure changes temporarily, spatially, or qualitatively, individuals which are able to respond flexibly to the actual risk (i.e., phenotypically plastic individuals) are predicted to have fitness advantages.

Predator-induced morphological defences are famous examples for phenotypic plasticity. They have been investigated in numerous taxa, especially in aquatic invertebrates (Harvell 1990; Tollrian and Harvell 1999; Chivers et al. 2008). However, plastic morphological responses to predators are less well documented in vertebrates. Here, research have focused mainly on tadpoles of different anuran species (e.g., McCollum and VanBuskirk 1996; Relyea 2001) and fishes of the genus Carassius. A classical field and laboratory study by Brönmark and Miner (1992) showed that predatory pikes (Esox lucius) induced an increase in body depth in crucian carp (Carassius carassius). Deep-bodied individuals seemed to have a reduced risk of predation relative to shallow-bodied conspecifics, because they showed enhanced escape performance, a higher percentage of muscle mass (Domenici et al. 2008), and were more difficult to handle for piscivores (Nilsson et al. 1995). However, the morphological changes also bear costs. Deep-bodied individuals were bad food competitors and suffered hydrodynamic costs (Pettersson and Brönmark 1997, 1999; Andersson et al. 2006). Recently, Chivers et al. (2008) demonstrated a similar anti-predator response in a closely related species, the goldfish (Carassius auratus). 
Three-spined sticklebacks (Gasterosteus aculeatus) are an ideal model system to study morphological anti-predator responses. They own a bony body armour and dorsal and pelvic spines which protects them against predators (e.g., Hoogland et al. 1956; Gross 1976). Still, they are typical prey species, with several fish, bird, and invertebrate species frequently predating on them (e.g., Gross 1976; Reimchen 1980; Kemper 1995). In some areas of the Baltic Sea, for example, they are the most abundant prey fish species (Mannki and Vauras 1974). Sticklebacks show considerable morphological and behavioural variation both within and between populations. Populations facing high levels of predation differ from predator-free populations in morphology (Bell and Foster 1994; Marchinko 2009). Differences in morphology are shown to have arisen by selective predation on more vulnerable phenotypes (e.g., Reimchen 1980, 2000), and are thus reflecting genetic differences. However, as a colonising and migratory species (e.g., Bell and Foster 1994), sticklebacks often face changes in their environment, like different diets or levels of predation pressure. Thus, there is a potential for the evolution of plastic responses. Indeed, sticklebacks have been shown to respond plastically (in morphological traits) to different environmental challenges (Day et al. 1994; Wund et al. 2008; Dingemanse et al. 2009). The present study had three objectives: First, we wanted to deepen our knowledge of phenotypic plastic responses to the risk of predation in a migratory population of threespined sticklebacks during early and late stages of their life. Second, we aimed to elucidate which cues sticklebacks use for predator recognition, and third we wanted to investigate potential costs of plastic responses.

\section{Materials and methods}

Experimental subjects and set-up

Three-spined sticklebacks from an anadromous, genetically heterogeneous population (Heckel et al. 2002) were caught during their spring migration in April 2002 on the island of Texel, the Netherlands. Here, they face predation pressure from different birds (Kemper 1995) and fishes, including perch (Perca fluviatilis; J. Hottentot, pers. communication), during their whole life. Perch, which were used as predatory fish, were caught from the floodplain of the River Rhine near the city of Rees, Germany. Roach (Rutilus rutilus), which were used as non-predatory fish, were caught from Lake Müggelsee, Berlin, Germany. All fishes were brought to the Institute for Evolutionary Biology and Ecology, Bonn, where they were kept in large (750 1) outdoor tanks.

Randomly chosen pairs of sticklebacks were allowed to spawn (see Frommen et al. 2008 for details). Clutches were taken out of the male's nest $1 \mathrm{~h}$ after spawning, clutch sizes ranged between approx. 110 and 300 eggs. In total 14 families were produced. Each clutch was split into three equal-sized sub-families which were placed in one liter containers in which larvae hatched. Right from the start of the experiment, eggs of the three sub-families were exposed to the respective fish odours, i.e., were reared in perch conditioned, roach conditioned or tap water, called "treatment-water" from now on (for the production of treatment-water see below). Tank water was completely exchanged daily with treatmentwater to reduce the risk of fungal infections (Frommen et al. 2008) and to ensure continuous exposure to the fish cues. At an age of 31 days groups were reduced to a size of 30 individuals and were transferred to larger tanks measuring $30 \mathrm{~cm} \times 20 \mathrm{~cm} \times 20 \mathrm{~cm}(1 \times \mathrm{w} \times \mathrm{h})$. Here they remained until an age of approximately 6 months. Thereafter, all sub-families of a treatment group were placed into one large tank $(100 \mathrm{~cm} \times 50 \mathrm{~cm} \times 40 \mathrm{~cm})$. All tanks 
were cleaned and aerated using internal filters (Dohse Aquaristik, Gelsdorf, Germany). Water in these tanks was exchanged 5 times a week by treatment-water (see below). Fry were fed living Artemia nauplii in excess which were replaced at an age of 12 weeks by defrosted adult Artemia and Chironomus larvae.

To produce the olfactory stimuli, i.e., treatment-water, for each family triplet group, three tanks measuring $50 \mathrm{~cm} \times 30 \mathrm{~cm} \times 30 \mathrm{~cm}$ were filled with aerated tap water and placed on a shelf above the stickleback tanks. In the first tank a single perch was placed (predator treatment), in the second a single roach (fish-control treatment). The third tank served as control treatment and contained no fish. Thus, corresponding to the 14 family triplet groups used, 14 perches (median body size, quartiles $(\mathrm{cm})$ : 5.7, 4.6, 6.45) and 14 roaches $(5.3,4.55$, $6.38)$ were used. They were size matched within each trial and did not differ significantly (Wilcoxon matched-pairs signed-ranks test, $Z=-1.689, P=0.091$ ). All fish were fed daily with defrosted Chironomus larvae. Each tank was connected to the tank containing the respective stickleback sub-families via a flexible tube. During the first 6 months approximately 151 of stimulus water was flushed daily into the rearing tanks, excessive water from the stickleback tanks drained off into a spillway system. After 6 months all perch and all roach were placed each into a group tank $(100 \mathrm{~cm} \times 50 \mathrm{~cm} \times 40 \mathrm{~cm})$. Thus, there was one tank containing olfactory stimulus of 14 perch, one containing stimulus of 14 roach and one containing tap water. From now on, 601 of stimulus water was added to the stickleback holding tanks 5 times a week. Adding stimulus water lasted approximately 15 min per tank. Thus, a habitat with predatory perch, a habitat with non-predatory fish and a fish-free habitat was simulated using olfactory cues only.

The fish were kept in an air-conditioned room under standardised summer light regime (day length $16 \mathrm{~L}: 8 \mathrm{D}$, temperature $16 \pm 1^{\circ} \mathrm{C}$ ). At an age of approximately 6 month the light-regime was changed to winter conditions (day length 8L:16D, temperature $16 \pm 1^{\circ} \mathrm{C}$ ) for 12 months to prevent fish from reaching the sexual phase (Borg et al. 2004). Afterwards, summer light conditions were re-established.

\section{Quantification of body shape and defensive morphology}

Standardised pictures of the lateral body and of the pelvic spines of all juvenile sticklebacks were taken at an age of $150 \pm 2$ days. For each specimen we took one lateral and one ventral picture together with a size standard of $30 \mathrm{~mm}$ length. Lateral pictures were made using a digital camera (Canon PowerShot G1 with macro lens) fixed on a tripod. To obtain standardised pictures of the pelvic spines the ventral body of each stickleback was arranged on a glass slide. This slide was placed upside down under a binocular, which was connected with a digital camera (HV-C20AMP, Hitachi Denshi Ltd). Pictures were taken through the glass. Again, a size standard of $30 \mathrm{~mm}$ length was included in each spine picture. Additionally, all fish were weighed to the nearest milligram. For analyses we calculated the body condition as $\mathrm{BC}=100 \mathrm{mass}(\mathrm{g}) / \mathrm{standard}$ length $(\mathrm{cm})^{3}$, following Bolger and Connolly (1989). Afterwards, fish were returned to their holding tanks. At an age of 30 months, adult individuals were killed in chlorobutanol (1,1,1-trichloro-2-methoy2-propanol) and photographed and weighed again as described before. Additionally, sexes were determined by visual judgement.

Body shape was quantified from lateral pictures using a set of 16 homologous landmarks (Fig. 1), using the tps software (Rohlf 2003). The standard length was measured as the distance between landmarks 1 and 13. The length of the first two dorsal and both pelvic spines were measured two times from the pictures using the software ImageJ 1.34 (Abramoff et al. 2004). For analysis we used the mean value of each spine. 
Fig. 1 Positioning of the landmarks used in geometric morphometric analyses

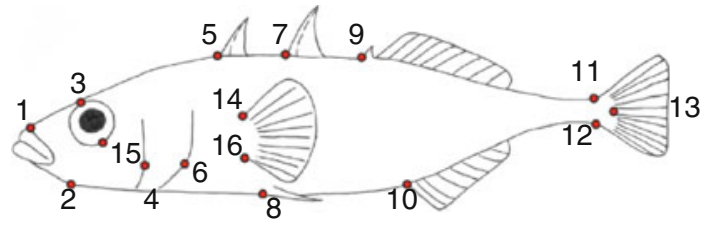

Statistical analyses

Body measures

Data were analysed using R 2.4.1 (Ihaka and Gentleman 1996). Because of a technical error, pictures of six juvenile sibling groups were lost. Thus, the analyses of juveniles were based only on 8 families. For analyses of juvenile measurements, family was entered as random factor. Because adults were no longer kept in family groups this was not done for analyses of adults. Due to juvenile mortality the original sample size was reduced. In total we analysed 80 fish from perch conditioned water, 106 from roach conditioned water, and 102 from tap water. Group size did not differ significantly between treatment groups (mean $\pm \mathrm{SD}$, perch: $12.8 \pm 6.5$, roach: $13.2 \pm 5.5$, tap water: $10.0 \pm 8.4 ; F_{2,6}=1.48$, $P=0.3$ ). Nevertheless, as also shown in many other fish species (e.g., Holopainen et al. 1997), group size significantly influenced body length $(P<0.01)$ and was therefore included in all final models to control for this source of residual variance. We applied mixed-effect linear models using the lme function of the nlme library (Pinheiro and Bates 2000). This routine uses maximum likelihood parameter estimation. Tests of statistical significance were based on likelihood ratio tests, which follow a $\chi^{2}$-distribution.

We analysed body circumference as the summed length of the left and right pelvic spine, the first dorsal spine and body height, where body height was defined as the distance between the pelvic spine and the first dorsal spine (landmarks 5 and 8, see Fig. 1). At both the juvenile and adult stage, the length of all four spines correlated strongly within individuals (for juveniles all $r>0.73$, all $P<0.0001$; for adults all $r>0.64$, all $P<0.0001$ ). We therefore, performed a principal component analysis in order to obtain a one-dimensional variable of spine length, which was then used for subsequent analyses. To measure pelvic spine asymmetries we used the absolute differences between the length of right and the left spine. When testing for treatment effects, a first omnibus test was carried out. If this test indicated significant differences between groups, three pairwise Sidak-adjusted posthoc tests were performed (Sokal and Rohlf 1995).

\section{Body shape}

Effects of size and position were removed from the data using the "Generalized Procrustes Analysis" procedure (Zelditch et al. 2004) implemented in the IMP software package (Sheets 2002). After superimposition, the data were translated into Partial Warps using the thin-plate spline model (Bookstein 1989). These linearly transformed variables are suitable for use with standard multivariate statistical methods, since they carry the same number of variables as degrees of freedom (Zelditch et al. 2004). In a first step, variance in shape according to experimental treatments was estimated by a multivariate analysis of variance (MANOVA) using CVAgen6o (Sheets 2002). All PCs with more than 2\% explanatory power were then tested separately for homogeneity of variance using one-way ANOVA 
followed by Tukey HSD post-hoc tests in case of equal or Welch tests with Dunnet T3 post-hoc tests in case of unequal variances implemented in PAST v. 1.70. (Hammer et al. 2001). The whole procedure was carried out for juvenile and adult sticklebacks separately. Differentiation in shape between adult groups was visualised as displacement vector for each landmark on a deformation grid relative to a reference.

\section{Results}

Juvenile body measures

The PC-analysis yielded one single significant factor (PC1, Eigenvalue: 3.75; proportion of variance: $93.5 \%$ ). This principal component 1 is a combined score of all four spine lengths. High scores are associated with long spines (factor loadings: left pelvic spine 0.977, right pelvic spine 0.976 , first dorsal spine: 0.949 , second dorsal spine, 0.966). When controlling for family descent and group size, rearing condition significantly influenced both standard length, body mass as well as the condition of juvenile fish (Table 1; Fig. 2). Juveniles from the perch water treatment were larger and heavier than the juveniles from both the roach water and from the tap water treatment (Table 1; Fig. 2, all $P<0.0001$ ), whereas there were no significant differences between the roach and the tap water treatment (standard length: $P=0.40$; mass: $P=0.37$, Table 1 ). Juveniles from the perch water treatment were in significantly better body condition than the juveniles from the roach water treatment $(P=0.0003)$, whereas juveniles from the tap water treatment were in intermediate condition (perch vs. tap water: $P=0.67$; roach vs. tap water: $P=0.056$ ).

Additionally, in juveniles, treatment also significantly influenced spine length, body circumference, eye width, but not pelvic spine asymmetry (Table 1). Juveniles from the

Table 1 Results of a mixed-effect linear model analysing the effect of juvenile rearing condition on various body measures

\begin{tabular}{lccccc}
\hline & \multicolumn{1}{l}{ Perch } & \multicolumn{1}{l}{ Roach } & Tap water & $\chi^{2}$ & $P$ \\
\hline Standard length & $26.67 \pm 0.60^{\mathrm{a}}$ & $25.17 \pm 0.50^{\mathrm{b}}$ & $24.8 \pm 0.51^{\mathrm{b}}$ & 27.4 & $<\mathbf{0 . 0 0 0 1}$ \\
Body weight & $0.289 \pm 0.020^{\mathrm{a}}$ & $0.220 \pm 0.017^{\mathrm{b}}$ & $0.211 \pm 0.017^{\mathrm{b}}$ & 42.9 & $<\mathbf{0 . 0 0 0 1}$ \\
Body condition & $1.375 \pm 0.040^{\mathrm{a}}$ & $1.285 \pm 0.033^{\mathrm{b}}$ & $1.347 \pm 0.034^{\mathrm{ab}}$ & 13.6 & $\mathbf{0 . 0 0 1}$ \\
Spine length (PC1) & $0.298 \pm 0.172^{\mathrm{a}}$ & $-0.018 \pm 0.141^{\mathrm{b}}$ & $-0.064 \pm 0.145^{\mathrm{b}}$ & 12.8 & $\mathbf{0 . 0 0 2}$ \\
Body circumference & $25.34 \pm 0.70^{\mathrm{a}}$ & $23.68 \pm 0.58^{\mathrm{b}}$ & $23.50 \pm 0.60^{\mathrm{b}}$ & 23.0 & $<\mathbf{0 . 0 0 0 1}$ \\
Eye width & $2.584 \pm 0.046^{\mathrm{a}}$ & $2.467 \pm 0.038^{\mathrm{b}}$ & $2.429 \pm 0.039^{\mathrm{b}}$ & 28.4 & $<\mathbf{0 . 0 0 0 1}$ \\
Spine asymmetry & $0.136 \pm 0.026$ & $0.112 \pm 0.021$ & $0.125 \pm 0.022$ & 2.46 & 0.29 \\
Controlled for standard length variation & & & & \\
Spine length (PC1) & $-0.0216 \pm 0.092$ & $0.0072 \pm 0.071$ & $0.0470 \pm 0.072$ & 1.57 & 0.46 \\
Body circumference & $24.03 \pm 0.38$ & $23.81 \pm 0.30$ & $24.00 \pm 0.30$ & 2.57 & 0.28 \\
Eye width & $2.49 \pm 0.023$ & $2.48 \pm 0.018$ & $2.47 \pm 0.018$ & 3.79 & 0.15 \\
Spine asymmetry & $0.135 \pm 0.026$ & $0.112 \pm 0.021$ & $0.126 \pm 0.021$ & 2.38 & 0.30 \\
\hline
\end{tabular}

In the analysis presented in the upper panel, family descent (random effect) and group size were entered as controlling factors. Parameter estimates are given by the adjusted mean values $\pm \mathrm{CI}$; in the upper panel for mean group size 15.67, in the lower panel for mean standard length 25.35. Tests for statistical significance are based on the difference in $\log$-likelihood $(d f=2)$ from the full model $(d f=6)$. Means with the same superscript letter do not differ significantly

Significant differences $(P<0.05)$ are given in bold 

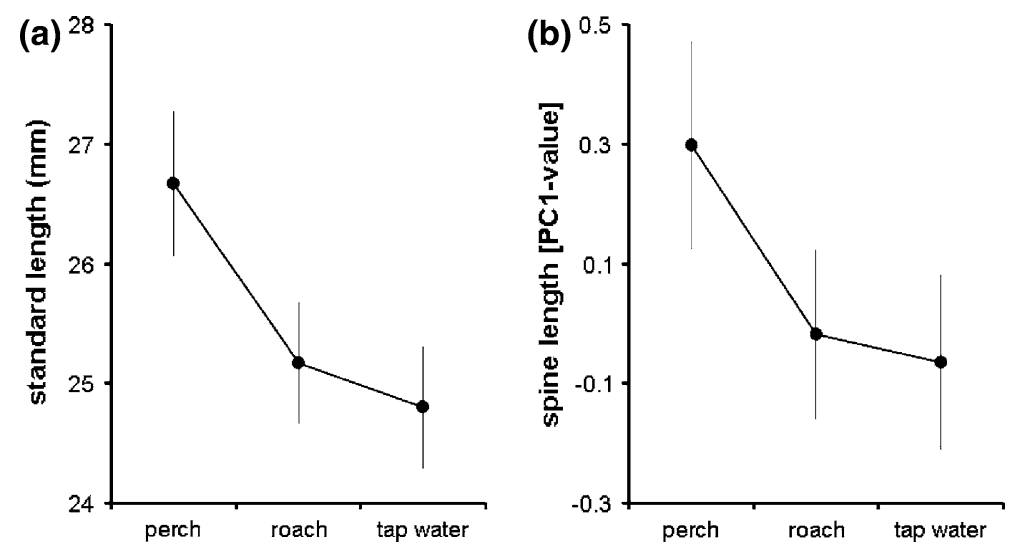

Fig. 2 The effect of rearing conditions on a juvenile standard length and $\mathbf{b}$ juvenile spine length. Estimates are given as mean $\pm \mathrm{CI}$

perch water treatment had significantly longer spines, wider body circumference, and larger eyes than the individuals from the roach (spine length: $P=0.007$; body circumference: $P<0.0001$; eye width: $P<0.0001$ ) and the tap water treatment (spine length: $P<0.002$; body circumference: $P<0.0001$; eye width: $P<0.0001)$. The roach and the tap water individuals, however, did not differ significantly in any of these measures (spine length: $P=0.90$; body circumference: $P=0.82$; eye width: $P=0.20$ ). Standard length was significantly associated with all these measures except for pelvic spine asymmetry (spine length: $0.23 \pm 0.007, \chi^{2}=425.0, \quad d f=1, P<0.0001$; body circumference: $0.98 \pm 0.02, \chi^{2}=632.2, d f=1, P<0.0001$; eye width: $0.068 \pm 0.002, \chi^{2}=483.7$, $d f=1, P<0.0001$; pelvic spine asymmetry: $0.0005 \pm 0.0016, \chi^{2}=0.094, d f=1, P=$ $0.76)$. When controlling for this variation in standard length by entering it as a covariate in the analyses, there was no significant effect of juvenile rearing condition on any of the traits measured (Table 1). Thus, perch water individuals differed in the absolute measures of spine length, body circumference and eye width but not relative to body standard length (Table 1).

Juvenile body shape

Juvenile sticklebacks from the three different rearing regimes could be separated along the first two CV axes. The first axis separates sticklebacks reared under roach water conditions from the two other rearing conditions (axis 1: Lambda $=0.66, \chi^{2}=114.02, d f=56$, $P<0.001$ ), the second axis separates the perch water treatment from the two other treatments (Axis 2: Lambda $=0.84, \chi^{2}=47.14, d f=27, P=0.01$ ). Shape variation in both $\mathrm{CV}$ axes loaded mainly on a composition of body depth (relative vertical position of dorsal spine landmarks 5, 7, 9 vs. anal fin origin landmark 10; CV1 and CV2) and head shape (mainly orientation of snout landmarks 1,2 in CV1; a composition of snout orientation and head depth by mainly vertical variation in landmarks 4 and 15 vs. 3 in CV2; see Fig. 1 for landmarks). Comparisons of eight single principal components with more than $2 \%$ explanatory power for the respective groups revealed no significant differences between the three rearing conditions (one-way ANOVA, all $P>0.05$ ). 
Adult body measures

For adults, the PC-analysis yielded a single significant factor (PC1, Eigenvalue: 3.21, proportion of variance: $80.4 \%$; factor loadings: left pelvic spine 0.923 , right pelvic spine 0.904, first dorsal spine: 0.888 , second dorsal spine, 0.870). Both standard length and body condition but not body mass were significantly influenced by rearing condition (Table 2). Adult sticklebacks reared in tap water were significantly smaller than the adults from the other treatments (both $P<0.05$ ), yet were of similar mass and thus in better condition (both $P<0.0001$ ). Perch water and roach water individuals did not significantly differ in any respect (standard length: $P=0.99$; Fig. 3; condition: $P=0.13$ ).

In contrast to the juvenile measurements, neither adult spine length, nor body circumference, nor eye width differed significantly between treatments (Table 2). However, pelvic spine asymmetry was significantly influenced by rearing conditions (Table 2; Fig. 3). Adults from the perch water treatment had significantly more asymmetrical pelvic spines than adults from the roach water treatment $(P=0.013)$ and from the tap water treatment $(P=0.005)$. These differences remained significant when differences in standard body length were controlled for. When controlling for standard length, adults reared in tap water had significantly longer spines than sticklebacks reared in perch water (Table 2, $P=0.021$ ). Thus tap water adults were smaller than perch water adults but showed relatively longer spines. Furthermore, there were significant differences between the sexes (Table 2), with males being smaller and showing higher condition factors.

Adult body shape

The CVA/MANOVA revealed two significant axes separating the three treatment groups. The first axis separated tap water specimens from both perch and roach water sticklebacks (Lambda $=0.082, \chi^{2}=170.35, d f=56, P<0.001,84.39 \%$ explanatory power; Fig. 4), whereas the second axis separated perch water specimens from the two other groups (Lambda $=0.52, \chi^{2}=45.39, d f=27, P=0.015,15.61 \%$ explanatory power; Fig. 4). Adult sticklebacks reared under perch and roach water conditions differed mainly in body depth from the tap water treatment group (Fig. 4, CV1). The perch water treatment sticklebacks differed from the other two groups, mainly in head parameters and minor shape differences concentrated to the back region (Fig. 4, CV2).

In order to evaluate whether the observed differentiations were biased by imbalanced sampling, regressions between the CVA scores and centroid size were carried out. Linear regressions revealed no significant effect of size (CV1 vs. size: $r=-0.16, P=0.14$; CV2 vs. size: $r=-0.01 P=0.91)$, meaning that the observed differentiation cannot be explained by size. Comparisons of eight single Principal Components with more than $2 \%$ explanatory power for the respective groups revealed significant differences in Principal Components 1, 3 and 5 (Table 3). PC 1 separated all treatment groups from each other (Fig. 5; Table 3), PC3 separated tap water from perch and roach water (Table 3), PC5 separated tap water and roach water sticklebacks (Table 3). Analysing male and female fish separately did not change the described pattern (data not shown).

\section{Discussion}

The present study focused on the hypothesis that in three-spined sticklebacks predator odours induce part of the variation in morphological anti-predator traits, like already 


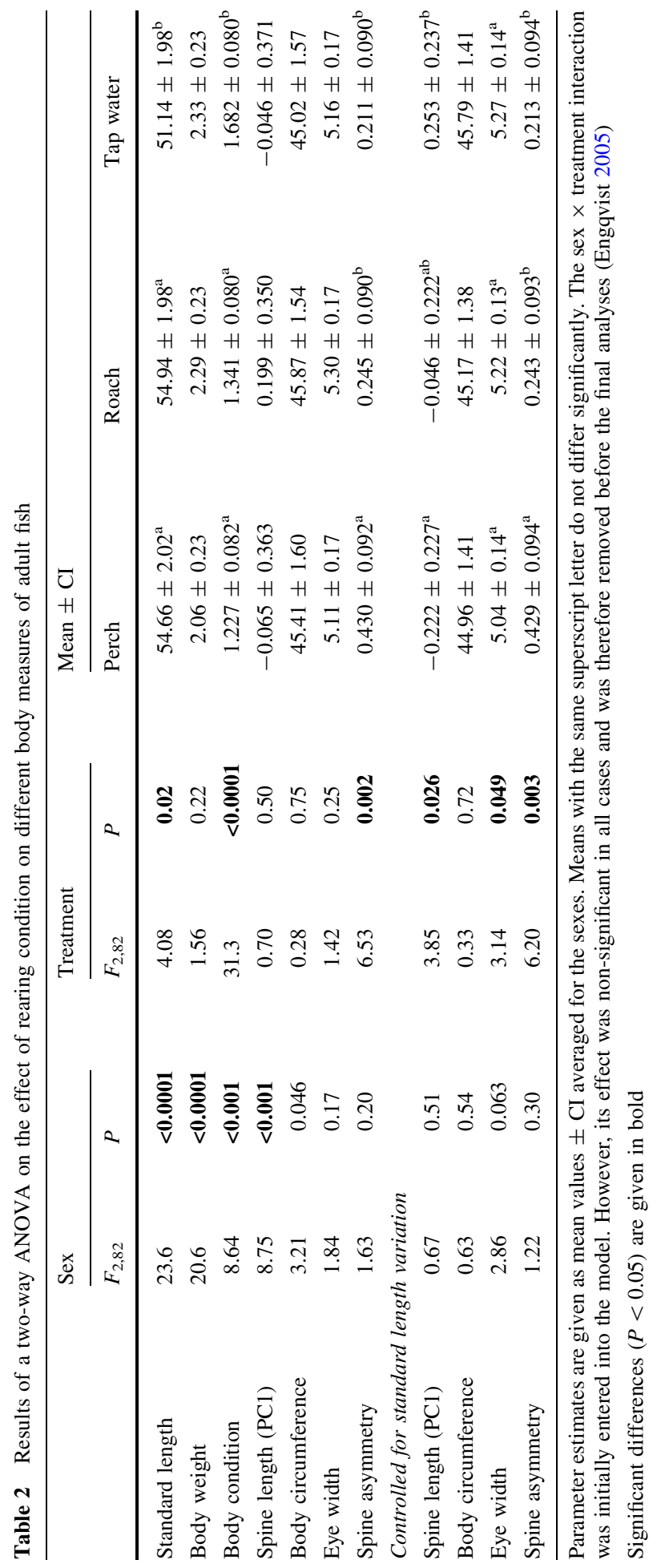



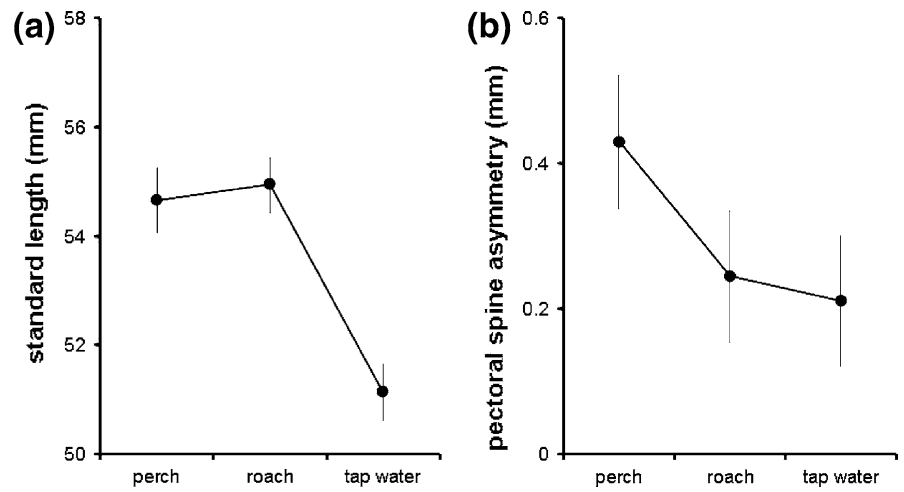

Fig. 3 The effect of rearing conditions on a adult standard length and $\mathbf{b}$ adult pelvic spine asymmetry. Estimates are given as mean $\pm \mathrm{CI}$

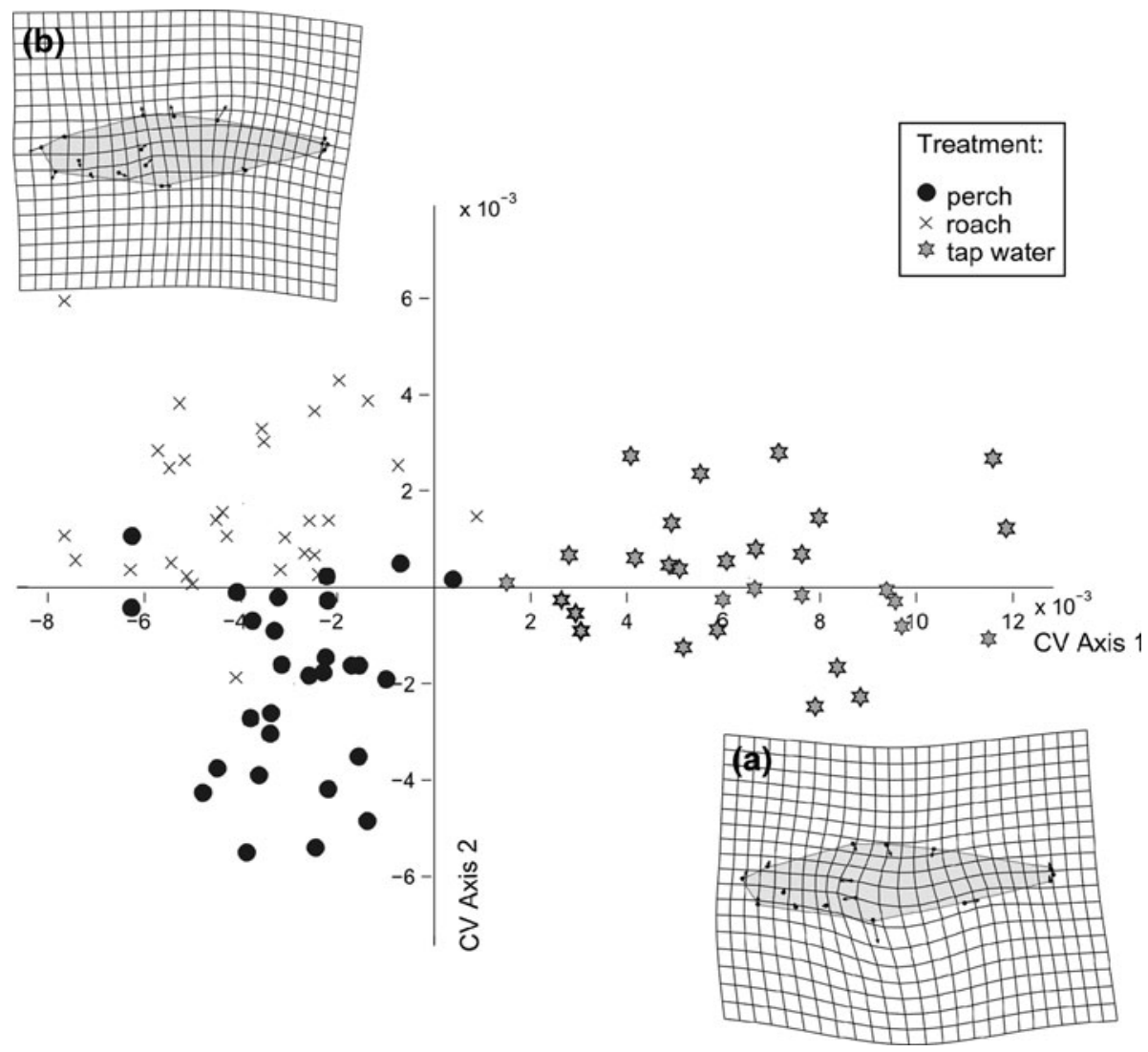

Fig. 4 Differentiation of the three treatment groups of adult sticklebacks along the first two CV axes. Deformation grid with displacement vectors for CV1 (a) and CV2 (b) 
Table 3 Results of the one-way ANOVA and Tukey's pairwise comparisons on differences in body shape between the three treatment groups of adult sticklebacks

\begin{tabular}{|c|c|c|c|c|c|c|c|c|}
\hline & PC1 & PC2 & PC3 & PC4 & PC5 & PC6 & PC7 & PC8 \\
\hline \multicolumn{9}{|l|}{ Anova } \\
\hline$F_{2,84}$ & 14.17 & 1.29 & 22.34 & 2.69 & 4.56 & 0.20 & 0.27 & 0.07 \\
\hline$P$ & $<0.0001$ & 0.28 & $<0.0001$ & 0.074 & 0.013 & 0.82 & 0.27 & 0.93 \\
\hline \multicolumn{9}{|c|}{ Posthoc perch vs. roach } \\
\hline$Q$ & 3.91 & 1.88 & 2.00 & 1.17 & 1.28 & 0.79 & 1.04 & 0.45 \\
\hline$P$ & 0.019 & 0.38 & 0.34 & 0.69 & 0.64 & 0.84 & 0.25 & 0.95 \\
\hline \multicolumn{9}{|c|}{ Posthoc perch vs. tap water } \\
\hline$Q$ & 3.55 & 0.16 & 8.95 & 2.03 & 2.85 & 0.78 & 0.65 & 0.49 \\
\hline$P$ & 0.037 & 0.99 & $<0.0001$ & 0.33 & 0.12 & 0.85 & 0.89 & 0.94 \\
\hline \multicolumn{9}{|c|}{ Posthoc tap water vs. roach } \\
\hline$Q$ & 7.46 & 2.04 & 6.96 & 3.21 & 4.13 & 0.006 & 0.38 & 0.004 \\
\hline$P$ & $<0.0001$ & 0.16 & $<0.001$ & 0.066 & 0.0125 & $>0.99$ & 0.96 & $>0.99$ \\
\hline
\end{tabular}

Eight principal components comprising most explanatory power $(>2 \%)$ were tested

Significant differences $(P<0.05)$ are given in bold

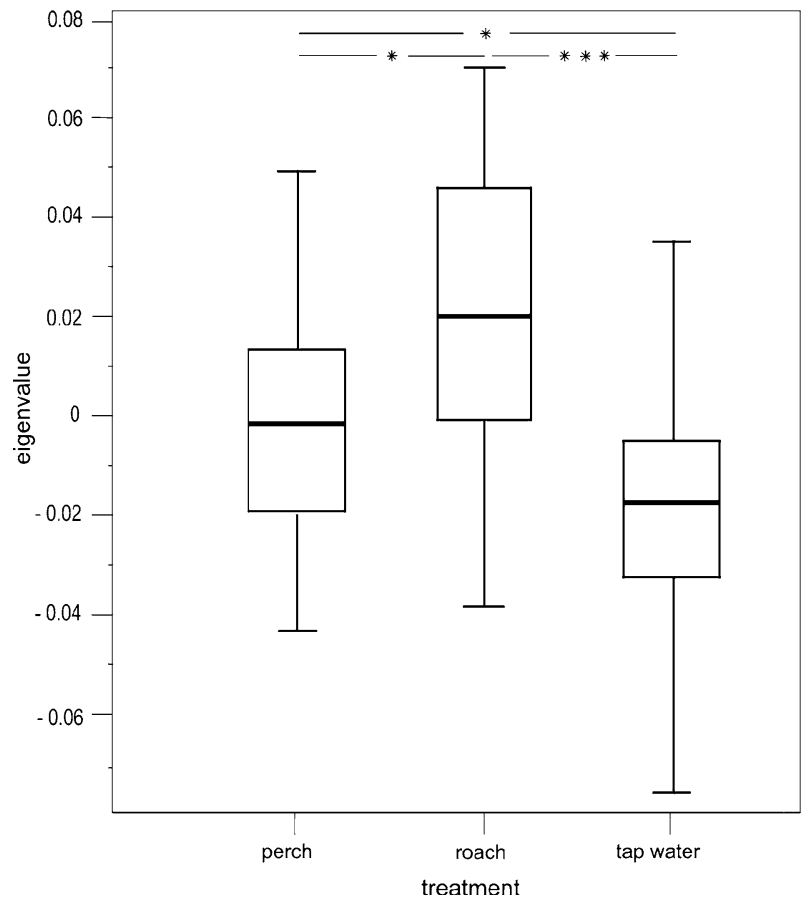

Fig. 5 Boxplots showing the differentiation between the treatment groups of adult sticklebacks in the first principal component, comprising for $46 \%$ of the total variance

demonstrated in other animal species (e.g., Brönmark and Miner 1992; Holopainen et al. 1997; Lass and Spaak 2003; Hettyey et al. 2010). Body shape, spine length, condition factor and standard length of juveniles and adults were quantified after rearing full-sibs 
under regular perch water (predator-treatment), roach water (non-predator-treatment, fish control) and tap water treatment (treatment control). Three character complexes showed significant differences between perch water and tap water treatments, but also indicated a response to roach odour compared to tap water controls. Juvenile sticklebacks grew significantly faster when exposed to perch odour than under both control treatments. Fast growth is a widespread strategy in prey animals to reduce predation risk (see Relyea 2007 for a review). The increased growth rate came along with significantly longer dorsal and pelvic spines (Table 1; Fig. 2). Higher juvenile growth rates were however correlated with enhanced levels of spine asymmetry (Table 2). Both groups reared under fish odour had deeper bodies compared to the tap water treatment (Table 3; Fig. 4).

A plastic response to predation pressure by developing an increased body depth as was observed here has also been reported from other fish, e.g., crucian carp and goldfish (Brönmark and Miner 1992; Chivers et al. 2007; Chivers et al. 2008). There, the phenomenon has been discussed as defence against gape-limited predators or as adaptation allowing enhanced turning rates, which are expected to improve chances for escaping from fish predators (Webb 1984; Sibbing and Nagelkerke 2001; Domenici et al. 2008). Following these ideas, sticklebacks with deeper bodies should show increased survival compared to slender ones when facing fish predation; deeper bodies should however be costly in terms of hydrodynamics, foraging efficiency and also have possibly metabolic costs (DeWitt et al. 1998; Relyea 2002b; Andersson et al. 2006). Plastic pathways of response to environmental cues during development should be clearly advantageous compared to fixed genetic responses when predatory regimes are variable (Miner et al. 2005). This is likely the case in the migrating stickleback population analysed here: individuals have to cope with a wide array of alternative habitats, associated to a likewise wide array of fish- and other predators. Predominantly heritable specialisation by adaptive divergence would in contrast lead to alternatively specialised populations in which individuals mate assortatively (Dieckmann et al. 2004; Gavrilets 2004). In fact, adaptive divergence driven by ecological selection pressure is well documented in various classic examples of lake-dwelling sticklebacks (Schluter 2000; Bolnick and Lau 2008), as well as in migrating-resident stickleback pairs (McKinnon et al. 2004), and in different resident lake or riverine populations (Reusch et al. 2001; Hendry et al. 2009 for a review).

Adult fish reared in roach water were of comparable size to fish reared in perch water but larger than fish reared in tap water. An explanation for this might be that juvenile roach and sticklebacks often have similar diets (Horppila and Nurminen 2009) and thus are competing for food. The larger size of roach water fish might thus be a response to a perceived amount of competition. In crucian carp for example both predation risk and intraspecific competition has been shown to influence morphology (Holopainen et al. 1997). A similar pattern has been described in wood frog tadpoles (Rana sylvatica) which developed larger bodies and smaller tails, both in the presence of conspecific and heterospecific competitors (Relyea 2002a).

Juvenile fish reared in perch water grew faster and had larger absolute spine length than fish reared in tap water (Figs. 2, 3). However, for adults these patterns changed. Fish in the predator-treatment were still larger, yet spine length was similar between treatments. Thus, fish reared in tap water had even larger relative spine length than fish from the predatortreatment (Table 2). An explanation for this seemingly counter-intuitive result could be that there might be an optimal spine length, beyond which spines become weaker and more fragile. Fish reared in perch water, which grow larger as an adaptive response to predation pressure, thus ultimately, have spines which are similar in absolute length, but smaller 
relative to body size. This result suggests that absolute spine length might not be plastic but rather genetically fixed and cannot be further increased in the examined population.

The influence of environmental stress on developmental stability has been described in a wide range of organisms (Parsons 1990; Møller and Swaddle 1997). The present correlation of asymmetry, growth rate and increasing body depth is most likely caused by metabolic constraints arising from plastic responses. The enhanced level of asymmetry accompanying increased growth and body depth might be a direct consequence of energetic costs required for this response causing development instability (Relyea 2002b). As female sticklebacks are known to prefer symmetric males as mating partners (Mazzi et al. 2003), asymmetries might be a cost of fast growing. Individuals, thus, might face a tradeoff between morphological anti-predator responses and attractiveness. On the other hand, significant departures from bilateral symmetry might also be explained by direct selection (Reimchen and Bergstrom 2009).

Morphological modifications in prey species are usually triggered by chemical cues (Wisenden and Chivers 2006). Alarm cues released from damaged or consumed conspecifics have been shown to induce morphological defences in fish (e.g., Chivers et al. 2007; Januszkiewicz and Robinson 2007; Chivers et al. 2008). Although fish can assess predation risk by olfactory cues and behave accordingly (e.g., Kusch et al. 2004), it often remains unknown whether predators' own or prey-related cues induce morphological change in prey. Perch only induced plastic responses in crucian carp when fed on crucian carp, but not when fed on an invertebrate diet (Brönmark and Pettersson 1994). In concordance with this result, pike which were not fed on crucian carp failed to induce a response (Stabell and Lwin 1997). In contrast, the present study shows that sticklebacks are able to react morphologically to olfactory predator cues even when predators were fed on invertebrates. Furthermore, this response appeared to be highly specific, that is, the morphological changes varied whether the other fish species was a predator or not.

Acknowledgments We are grateful to Jan Hottentot, Jörg Freyhof and Peter Beeck for catching and Julia Böhm for caring for the fish. We thank Ricarda Modarressie, Ingolf Rick, Jobst Pfaender and Paul Alibert for discussion. An earlier version of the manuscript was greatly improved by the comments of Valentina Balzarini and two anonymous referees.

\section{References}

Abramoff MD, Magelhaes PJ, Ram SJ (2004) Image processing with ImageJ. Biophotonics Int 11:36-42 Andersson J, Johansson F, Söderlund T (2006) Interactions between predator- and diet-induced phenotypic changes in body shape of crucian carp. Proc R Soc Lond B 273:431-437

Bell MA, Foster SA (1994) The evolutionary biology of the threespine stickleback. Oxford University Press, Oxford

Bolger T, Connolly PL (1989) The selection of suitable indices for the measurement and analysis of fish condition. J Fish Biol 34:171-182

Bolnick DI, Lau OL (2008) Predictable patterns of disruptive selection in stickleback in postglacial lakes. Am Nat 172:1-11

Bookstein FL (1989) Principal warps-thin-plate splines and the decomposition of deformations. IEEE Trans Pattern Anal Mach Intell 11:567-585

Borg B, Bornestaf C, Hellqvist A, Schmitz M, Mayer I (2004) Mechanisms in the photoperiodic control of reproduction in the stickleback. Behaviour 141:1521-1530

Brönmark C, Miner JG (1992) Predator-induced phenotypical change in body morphology in crucian carp. Science 258:1348-1350

Brönmark C, Pettersson LB (1994) Chemical cues from piscivores induce a change in morphology in crucian carps. Oikos 70:396-402 
Chivers DP, Zhao XO, Ferrari MCO (2007) Linking morphological and behavioural defences: prey fish detect the morphology of conspecifics in the odour signature of their predators. Ethology 113:733-739

Chivers DP, Zhao XX, Brown GE, Marchant TA, Ferrari MCO (2008) Predator-induced changes in morphology of a prey fish: the effects of food level and temporal frequency of predation risk. Evol Ecol 22:561-574

Crispo E (2007) The Baldwin effect and genetic assimilation: revisiting two mechanisms of evolutionary change mediated by phenotypic plasticity. Evolution 61:2469-2479

Day T, Pritchard J, Schluter D (1994) A comparison of two sticklebacks. Evolution 48:1723-1734

DeWitt TJ, Sih A, Wilson DS (1998) Costs and limits of phenotypic plasticity. Trends Ecol Evol 13:77-81

Dieckmann U, Doebeli M, Metz JAJ, Tautz D (2004) Adaptive speciation. Cambridge University Press, Cambridge

Dingemanse NJ, van der Plas F, Wright J, Reale D, Schrama M, Roff DA, van der Zee E, Barber I (2009) Individual experience and evolutionary history of predation affect expression of heritable variation in fish personality and morphology. Proc R Soc Lond B 276:1285-1293

Domenici P, Turesson H, Brodersen J, Brönmark C (2008) Predator-induced morphology enhances escape locomotion in crucian carp. Proc R Soc Lond B 275:195-201

Endler JA (1995) Multiple-trait coevolution and environmental gradients in guppies. Trends Ecol Evol 10:22-29

Engqvist L (2005) The mistreatment of covariate interaction terms in linear model analyses of behavioural and evolutionary ecology studies. Anim Behav 70:967-971

Frommen JG, Luz C, Mazzi D, Bakker TCM (2008) Inbreeding depression affects fertilization success and survival but not breeding coloration in threespine sticklebacks. Behaviour 145:425-441

Gavrilets S (2004) Fitness landscapes and the origin of species. Princeton University Press, Princeton

Gross HP (1976) Natural selection by predators on the defensive apparatus of three-spined stickleback, Gasterostrus aculeatus L. Can J Zool 56:398-413

Hammer $\varnothing$, Harper DAT, Ryan PD (2001) PAST: paleontological statistics software package for education and data analysis. Palaeontol Electronica 4:9 pp

Harvell CD (1990) The ecology and evolution of inducible defenses. Q Rev Biol 65:323-340

Heckel G, Zbinden M, Mazzi D, Kohler A, Reckeweg G, Bakker TCM, Largiadèr CR (2002) Microsatellite markers for the three-spined stickleback (Gasterosteus aculeatus L.) and their applicability in a freshwater and an anadromous population. Conserv Genet 3:79-81

Hendry AP, Bolnick DI, Berner D, Peichel CL (2009) Along the speciation continuum in sticklebacks. J Fish Biol 75:2000-2036

Hettyey A, Zsarnóczai S, Vincze K, Hoi H, Laurila A (2010) Interactions between the information content of different chemical cues affect induced defences in tadpoles. Oikos 119:1814-1822

Holopainen IJ, Aho J, Vornanen M, Huuskonen H (1997) Phenotypic plasticity and predator effects on morphology and physiology of crucian carp in nature and in the laboratory. J Fish Biol 50:781-798

Hoogland R, Morris D, Tinbergen N (1956) The spines of sticklebacks (Gasterosteus and Pygosteus) as means of defence against predators (Perca and Esox). Behaviour 10:205-236

Horppila J, Nurminen L (2009) Food niche segregation between two herbivorous cyprinid species in a turbid lake. J Fish Biol 75:1230-1243

Ihaka R, Gentleman R (1996) R: a language for data analysis and graphics. J Comput Graph Stat 5:299-314

Januszkiewicz AJ, Robinson BW (2007) Divergent walleye (Sander vitreus)-mediated inducible defenses in the centrarchid pumpkinseed sunfish (Lepomis gibbosus). Biol J Linn Soc 90:25-36

Kemper JH (1995) Role of the three-spined stickleback Gasterosteus aculeatus L. in the food ecology of the spoonbill Platalea leucorodia. Behaviour 132:1285-1299

Kusch RC, Mirza RS, Chivers DP (2004) Making sense of predator scents: investigating the sophistication of predator assessment abilities of fathead minnows. Behav Ecol Sociobiol 55:551-555

Langerhans RB, Layman CA, Shokrollahi AM, DeWitt TJ (2004) Predator-driven phenotypic diversification in Gambusia affinis. Evolution 58:2305-2318

Lass S, Spaak P (2003) Chemically induced anti-predator defences in plankton: a review. Hydrobiologia 491:221-239

Mannki J, Vauras J (1974) Littoral fish populations after an oil tanker disaster in the Finnish SW archipelago. Ann Zool Fenn 11:120-136

Marchinko KB (2009) Predation's role in repeated phenotypic and genetic divergence of armor in threespine stickleback. Evolution 63:127-138

Mazzi D, Künzler R, Bakker TCM (2003) Female preference for symmetry in computer-animated threespined sticklebacks, Gasterosteus aculeatus. Behav Ecol Sociobiol 54:156-161

McCollum SA, VanBuskirk J (1996) Costs and benefits of a predator-induced polyphenism in the gray treefrog Hyla chrysoscelis. Evolution 50:583-593 
McKinnon JS, Rundle HD (2002) Speciation in nature: the threespine stickleback model systems. Trends Ecol Evol 17:480-488

McKinnon JS, Mori S, Blackman BK, David L, Kingsley DM, Jamieson L, Chou J, Schluter D (2004) Evidence for ecology's role in speciation. Nature 429:294-298

Miner BG, Sultan SE, Morgan SG, Padilla DK, Relyea RA (2005) Ecological consequences of phenotypic plasticity. Trends Ecol Evol 20:685-692

Møller AP, Swaddle JP (1997) Asymmetry, developmental stability, and evolution. Oxford University Press, Oxford

Nilsson PA, Brönmark C, Pettersson LB (1995) Benefits of a predator-induced morphology in crucian carp. Oecologia 104:291-296

Nosil P, Crespi BJ (2006) Experimental evidence that predation promotes divergence in adaptive radiation. Proc Natl Acad Sci USA 103:9090-9095

Parsons PA (1990) Fluctuating asymmetry—an epigenetic measure of stress. Biol Rev Camb Philos Soc 65:131-145

Peichel CL, Nereng KS, Ohgi KA, Cole BLE, Colosimo PF, Buerkle CA, Schluter D, Kingsley DM (2001) The genetic architecture of divergence between threespine stickleback species. Nature 414:901-905

Pettersson LB, Brönmark C (1997) Density-dependent costs of an inducible morphological defense in crucian carp. Ecology 78:1805-1815

Pettersson LB, Brönmark C (1999) Energetic consequences of an inducible morphological defence in crucian carp. Oecologia 121:12-18

Pfennig DW, Wund MA, Snell-Rood EC, Cruickshank T, Schlichting CD, Moczek AP (2010) Phenotypic plasticity's impacts on diversification and speciation. Trends Ecol Evol 25:459-467

Pigliucci M (2001) Phenotypic plasticity: beyond nature and nurture. Johns Hopkins University Press, Baltimore

Pinheiro JC, Bates DM (2000) Mixed effects models in S and S-plus. Springer, New York

Price TD, Qvarnström A, Irwin DE (2003) The role of phenotypic plasticity in driving genetic evolution. Proc R Soc Lond B 270:1433-1440

Reimchen TE (1980) Spine deficiency and polymorphism in a population of Gasterosteus aculeatus: an adaption to predators? Can J Zool 58:1232-1244

Reimchen TE (2000) Predator handling failures of lateral plate morphs in Gasterosteus aculeatus: functional implications for the ancestral plate condition. Behaviour 137:1081-1096

Reimchen TE, Bergstrom CA (2009) The ecology of asymmetry in stickleback defense structures. Evolution 63:115-126

Relyea RA (2001) Morphological and behavioral plasticity of larval anurans in response to different predators. Ecology 82:523-540

Relyea RA (2002a) Competitor-induced plasticity in tadpoles: consequences, cues, and connections to predator-induced plasticity. Ecol Monogr 72:523-540

Relyea RA (2002b) Costs of phenotypic plasticity. Am Nat 159:272-282

Relyea RA (2007) Getting out alive: how predators affect the decision to metamorphose. Oecologia 152: $389-400$

Reusch TBH, Wegner KM, Kalbe M (2001) Rapid genetic divergence in postglacial populations of threespine stickleback (Gasterosteus aculeatus): the role of habitat type, drainage and geographical proximity. Mol Ecol 10:2435-2445

Rohlf FJ (2003) TpsDig, digitize landmarks and outlines, version 1.39. Department of Ecology and Evolution, State University of New York at Stony Brook, New York

Scheiner SM (1993) Genetics and evolution of phenotypic plasticity. Ann Rev Ecol Syst 24:35-68

Schlichting CD, Pigliucci M (1998) Phenotypic evolution: a reaction norm perspective. Sinauer, Sunderland

Schluter D (2000) The ecology of adaptive radiation. Oxford University Press, Oxford

Sheets HD (2002) IMP-integrated morphometrics package. Canisius College, Buffalo, Department of Physics, New York

Sibbing FA, Nagelkerke LAJ (2001) Resource partitioning by Lake Tana barbs predicted from fish morphometrics and prey characteristics. Rev Fish Biol Fish 10:393-437

Sokal RR, Rohlf FJ (1995) Biometry, 3rd edn. W. H. Freeman \& Company, New York

Stabell OB, Lwin MS (1997) Predator-induced phenotypic changes in crucian carp are caused by chemical signals from conspecifics. Environ Biol Fish 49:145-149

Tollrian R, Harvell CD (1999) The ecology and evolution of inducible defenses. Princeton University Press, Princeton

Waddington CH (1942) The epigenotype. Endeavour 1:18-20

Webb PW (1984) Body form, locomotion and foraging in aquatic vertebrates. Am Zool 24:107-120 
West-Eberhard MJ (1989) Phenotypic plasticity and the origins of diversity. Ann Rev Ecol Evol Syst 20:249-278

Wisenden BD, Chivers DP (2006) The role of public chemical information in antipredator behaviour. In: Ladich F, Collins SP, Moller P, Kapoor BG (eds) Communication in fishes. Science Publisher, Enfield, pp 259-278

Wund MA, Baker JA, Clancy B, Golub JL, Foster SA (2008) A test of the "flexible stem" model of evolution: ancestral plasticity, genetic accommodation, and morphological divergence in the threespine stickleback radiation. Am Nat 172:449-462

Zelditch ML, Swiderski DL, Sheets HD, Fink WL (2004) Geometric morphometrics for biologists. Academic Press, London 